\title{
Sterilization of Female Rats by Neonatal Placement of Estradiol Micropellets in Anterior Hypothalamus
}

\author{
SHINJI HAYASHI \\ Endocrinology Division, National Cancer Center Research Institute, \\ Tsukiji 5-chome, Chuo-ku, Tokyo 104
}

\section{Synopsis}

\begin{abstract}
A pair of micropellets of a $1 \%$ or $10 \%$ estradiol $\left(\mathrm{E}_{2}\right)$-paraffin mixture (containing 0.2 or $2 \mu \mathrm{g} \mathrm{E}_{2}$, respectively) or paraffin alone were implanted subcutaneously or intracerebrally in 5-day-old female rats. Animals given $10 \% \mathrm{E}_{2}$ pellets became sterilized regardless of loci of the pellets. Of those which had received $1 \% \mathrm{E}_{2}$ pellets, only animals with micropellets in the anterior hypothalamus became sterilized. It is suggested that neuronal components which are affected irreversibly by neonatal estrogen treatment are localized in the anterior hypothalamus.
\end{abstract}

It is well established that administration of androgens or estrogens during the neonatal period evokes a sterility syndrome characterized by anovulation and persistent vaginal estrus (masculinization) in female rats in adulthood (For reviews, see Takewaki, 1962; Gorski, 1971; Arai, 1973). The finding of Wagner et al. (1966) that implantation of microcrystals of testosterone propionate (TP) in the hypothalamus of neonatal female rats resulted in a similar type of sterility was confirmed by later workers (Nadler, 1968, 1972; Sutherland and Gorski, 1972; Hayashi and Gorski, 1974). On the basis of his experiments of TP micropellet implantation in different brain regions, Nadler $(1968,1972)$ postulated that the site of action of androgen is in the ventromedialarcuate nucleus region and not in the preoptic-anterior hypothalamic region. By contrast, Hayashi and Gorski (1974) reported that the sites which are affected irreversibly by neonatal androgen administration are

Received for publication October 27, 1975. dispersed rather than restricted to small areas in the hypothalamus.

Evidence has been presented by several workers which indicates that conversion of androgens to estrogens in the hypothalamus may be important in inducing masculinization (Naftolin et al., 1971, 1972; Weisz and Gibbs, 1974 ; McDonald and Doughty, 1972a, 1973). However, Brown-Grant (1974) reported that masculinization of the hypothalamic activity could not be consistently blocked by antiestrogen MER-25. Intrahypothalamic implants of MER-25 also failed to inhibit the action of androgen on the hypothalamus given subcutaneously (Hayashi, 1974). Thus, the mechanism and mode of action of neonatal administration of androgen or estrogen involved in the induction of sterility still remain to be clarified.

The present experiments were conducted to study regional differences in estrogen sensitivity in the hypothalamus of neonatal rats. By applying micropellets of estrogenparaffin mixture, it was shown that the 
anterior part of the hypothalamus was the site responsible for the induction of sterility in adulthood.

\section{Materials and Methods}

Micropellets of estradiol $\left(\mathrm{E}_{2}\right)$-paraffin mixture (1\% or $10 \% \mathrm{E}_{2}$ by weight) were bilaterally implanted into the hypothalamus or other brain areas of 5-day -old female rats of the Sprague-Dawley strain. Procedures of intracranial implantation were the same as described previously (Hayashi, 1974).

To make pellets, paraffin (melting point: $38-44^{\circ}$ C), charcoal bone and $E_{2}$ in weight ratio of $94: 5: 1$ or $85: 5: 10$ were melted and mixed on a slide glass placed on a metal plate kept at a temperature slightly below $200^{\circ} \mathrm{C}$. Paraffin pellets containing $5 \%$ charcoal but not $E_{2}$ were used for sham implantation.

Operated pups were returned to their mothers after regaining consciousness and weaned at 22 days of age. They were examined daily for vaginal opening and smearing commenced immediately. When the rats reached 45 days of age, ovaries were examined by laparotomy.

To estimate the magnitude of ovarian compensatory hypertrophy $(\mathrm{OCH})$, the right ovaries were removed and weighed at 3 weeks before sacrifice performed at 111 days of age. At autopsy, weights of body and remaining ovary were noted in each rat. Ovaries were fixed in Bouin's solution, sectioned in paraffin and stained with Delafield's hematoxylin and eosin. Serial sections of ovaries were checked for the presence of corpora lutea (CL). Those bearing no fresh CL in their ovaries were grouped as sterilized. Brains perfused by buffered $10 \%$ formalin and fixed in the same solution were sectioned frozen in gelatin at $60 \mu \mathrm{m}$ and stained with carbol fuchsin. The location of the micropellets which have remained in the hypothalamus until the day of sacrifice was determined histologically.

Micropellets were weighed on an ultramicrobalance (Mettler ME-22) to the nearest $0.1 \mu \mathrm{g}$. Average weights ( \pm S.E.) of 11 pellets containing $10 \% \mathrm{E}_{2}$, $1 \% \mathrm{E}_{2}$ and no $\mathrm{E}_{2}$ were $18.5 \pm 0.4,19.9 \pm 0.8$ and $17.5 \pm 0.6 \mu \mathrm{g}$, respectively. Since pellets were implanted bilaterally, the amount of $E_{2}$ given to each animal was about 4 or $0.4 \mu \mathrm{g}$ on an average.

\section{Results}

Loci of micropellets directed toward the anterior hypothalamic nuclei (ha), dorsomedial hypothalamic nuclei (hdm), posterior hypothalamic nuclei (hp), paraventricular nuclei (hpv), the medial forebrain bundle (FMD), the central amygdala (ca), hippocampus (HI) or the cerebral cortex just above the truncus corporis callosi (TCC) were histologically verified. Implanted pellets were found, in the majority of cases, slightly shifted to one side. Loci of some intracerebral pellets are illustrated in Figs. 1-3. Fifteen rats which had received two pellets of $10 \% \mathrm{E}_{2}$ intracerebrally were invariably sterilized, regardless of locus of implantation. Similar pellets implanted subcutaneously were also effective in sterilizing the receipients (6 animals). Adult rats which had been given $1 \%$ pellets in the anterior part of the hypothalamus were sterilized, while those which had received $1 \%$ pellets subcutaneously, in the corticolimbic system or in the medial or the posterior part of the hypothalmus had CL in their ovaries and showed estrous cycles (Figs. 1 and 4, Table 1). All sham-operated and intact-control rats exhibited $\mathrm{CL}$ in their ovaries and ran vaginal cycles (Figs. 1-3, Table 1).

In sterilized females, the right ovaries weighed 14-20 mg and the left ovaries 25$28 \mathrm{mg}$. Both values were significantly smaller than those of intact control rats bearing CL (the right ovaries $40 \mathrm{mg}$ and the left ovaries $58 \mathrm{mg}$, on an average). Data for ovarian compensatory hypertrophy $(\mathrm{OCH})$ are too meager and too variable to be analyzed statistically, mean $\mathrm{OCH}$ varying from 37 to $82 \%$ (Table 1).

Vaginal opening was slightly advanced in rats which received $E_{2}$ pellets neonatally. In 6 of 30 rats given $1 \%$ pellets, vaginal orifice was formed by 22 days of age, and in all of the 21 animals having received 10\% $E_{2}$ pellets, the vagina was patent by 15 days of age. The findings strongly suggest a direct effect of $E_{2}$ on the developing vaginal cords (Fig. 4). 


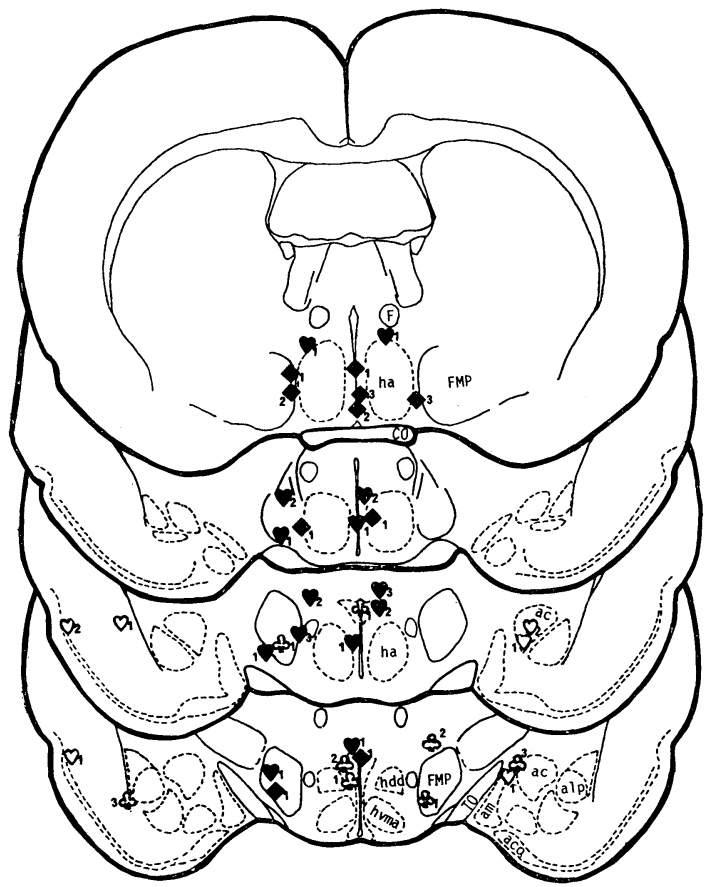

Fig. 1.

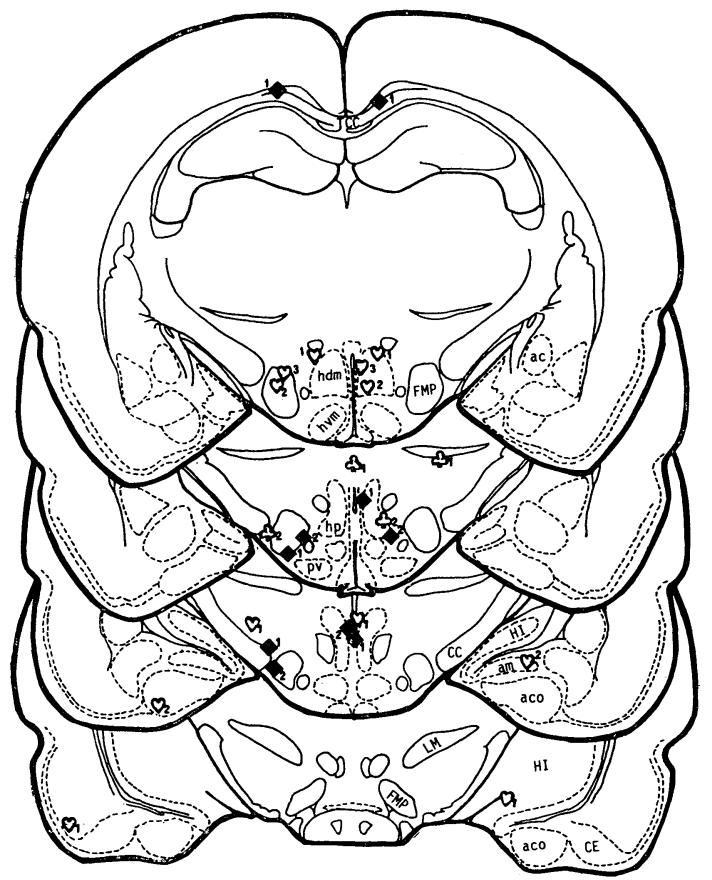

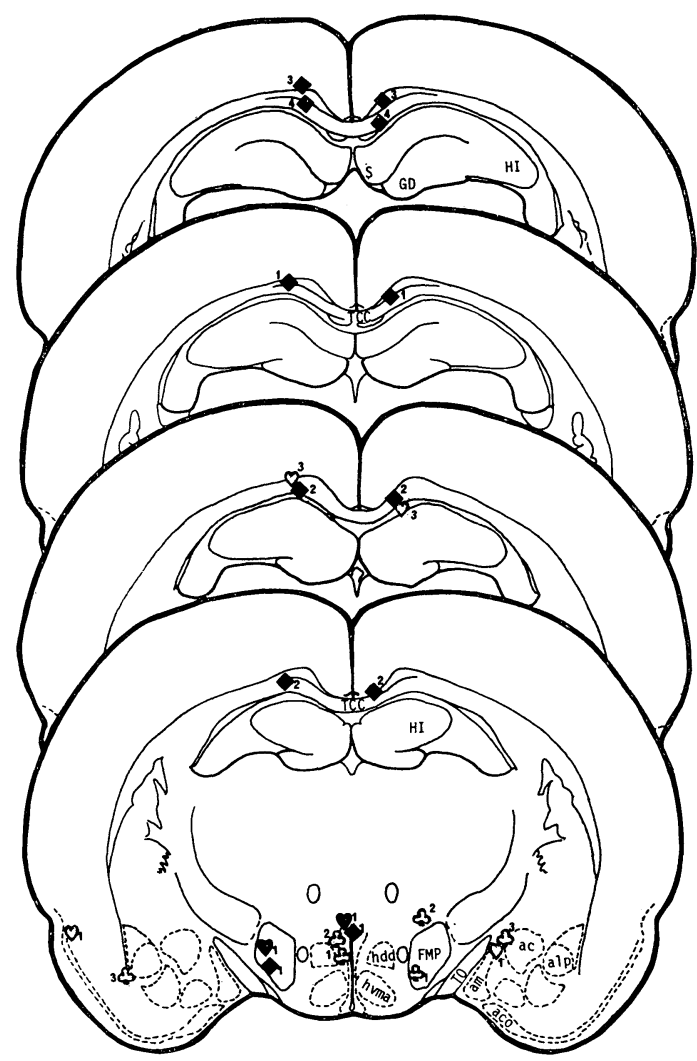

Fig. 3.

Figs. 1-3. Cross sections of brain illustrating loci of micropellets. Diamonds, hearts and clubs indicate pellets containing $10 \% \mathrm{E}_{2}, 1 \% \mathrm{E}_{2}$ and no $\mathrm{E}_{2}$, respectively. Dark ones: acyclic, anovulatory syndrome; open ones: normal cyclicity and ovulation. Paired pellets are marked with the same number. Abbreviations: FMP, medial forebrain bundle; HI, hippocampus; TCC, truncus corporis callosi; am, medial amygdala; ac, central amygdala; ha, anterior hypothalamic nucleus; hp, posterior hypothalamic nucleus; hvma, anterior part of ventromedial nucleus. For other abbreviations, see König and Klippel (1963).

Fig. 2. 


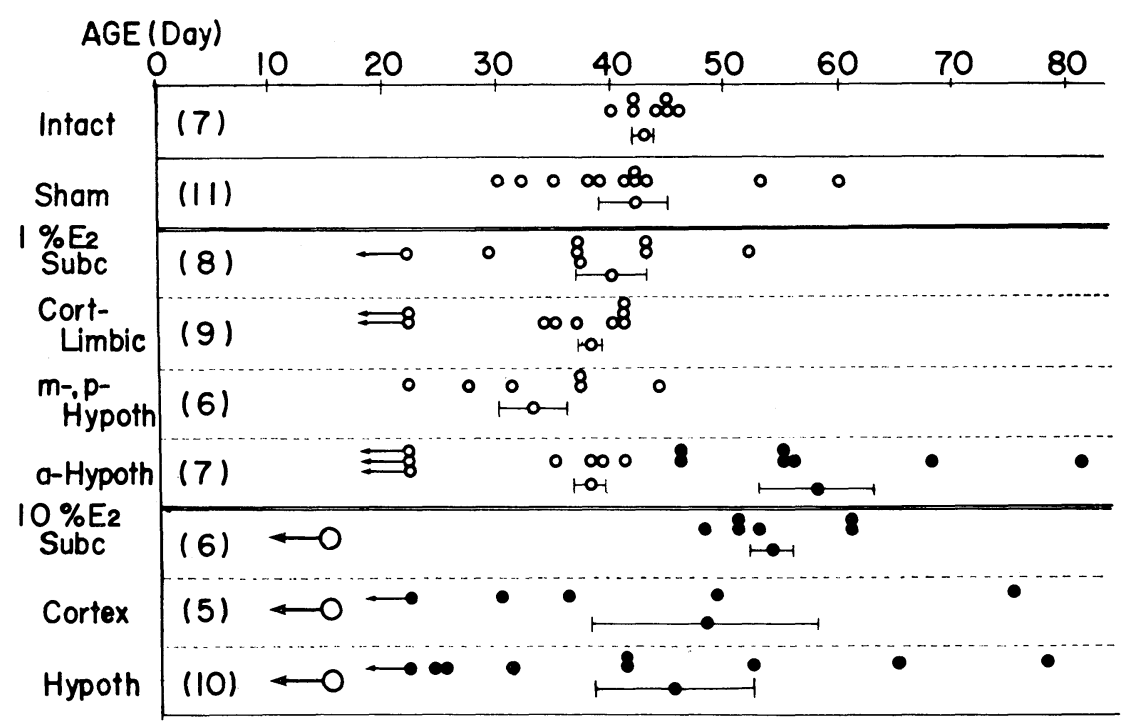

Fig. 4. Ages in days at vaginal opening (open circles) and at onset of persistent vaginal estrus (dark circles) of female rats receiving micropellets containing estradiol $\left(\mathrm{E}_{2}\right)$ intracerebrally or subcutaneously. Small circles represent individual animals. Six of those given $1 \% \mathrm{E}_{2}$ pellets had vaginal orifice at 22 days of age when examination for vaginal opening was begun (shown by open circles with arrow). All rats bearing $10 \% \quad \mathrm{E}_{2}$ pellets had the vaginae patent at 15 days of age. Mean \pm S.E. of ages available for each group of rats is shown in the lower part of each row. Figures in parentheses are number of animals. Loci of pellets containing $1 \%$ or $10 \% \mathrm{E}_{2}$ : Subc=subcutaneously on the head; Cort-limbic=in cortex, amygdala or hippocampus (Figs. 1-3); m-, p-Hypoth=in medial or posterior hypothalamus including hdm, hp (Fig. 2); a-Hypoth=in anterior hypothalamus including ha, FMP and paraventricular nucleus (Fig. 1); Hypoth=in area covering m-, p-Hypoth and a-Hypoth.

Table 1. Body weights at sacrifice, ovarian weights, ovarian compensatory hypertrophy (OCH) and incidence of sterility (IS) at 90 days of age in rats implanted with estradiol $\left(\mathrm{E}_{2}\right)$-micropellets subcutaneously or intracerebrally at 5 postnatal days.

\begin{tabular}{|c|c|c|c|c|c|c|}
\hline \multirow{2}{*}{$\begin{array}{l}\text { Experimental } \\
\text { groupsa }\end{array}$} & \multirow{2}{*}{$\begin{array}{l}\text { No. of } \\
\text { rats }\end{array}$} & \multirow{2}{*}{$\begin{array}{l}\text { Body weight } \\
\text { (g) }\end{array}$} & \multicolumn{2}{|c|}{ Ovarian weight (mg) } & \multirow{2}{*}{$\begin{array}{c}\mathrm{OCHb} \\
(\%)\end{array}$} & \multirow{2}{*}{$\begin{array}{l}\text { IS c } \\
(\%)\end{array}$} \\
\hline & & & Right & Left & & \\
\hline Intact & 7 & $245 \pm 6 d$ & $40.4 \pm 2.8$ & $58.0 \pm 3.6$ & $46 \pm 9$ & 0 \\
\hline Sham & 11 & $222 \pm 7$ & $35.2 \pm 1.6$ & $50.2 \pm 2.4$ & $46 \pm 7$ & 0 \\
\hline \multicolumn{7}{|l|}{$1 \% \mathrm{E}_{2}$ pellets } \\
\hline Subc & 8 & $256 \pm 9$ & $39.6 \pm 5.0$ & $65.0 \pm 5.4$ & $72 \pm 14$ & 0 \\
\hline Cort-limbic & 9 & $249 \pm 5$ & $38.5 \pm 1.6$ & $59.4 \pm 3.7$ & $56 \pm 9$ & 0 \\
\hline m-, p-Hypoth & 6 & $242 \pm 19$ & $36.1 \pm 3.0$ & $57.1 \pm 2.9$ & $61 \pm 10$ & 0 \\
\hline a-Hypoth & 7 & $251 \pm 9$ & $19.1 \pm 1.5^{* *}$ & $26.1 \pm 2.4^{* *}$ & $37 \pm 5$ & 100 \\
\hline \multicolumn{7}{|l|}{$10 \% \mathrm{E}_{2}$ pellets } \\
\hline Subc & 6 & $297 \pm 9 * *$ & $17.9 \pm 2.5^{* *}$ & $27.4 \pm 2.9^{* *}$ & $58 \pm 11$ & 100 \\
\hline Cort & 5 & $299 \pm 15^{*}$ & $20.1 \pm 3.5^{*}$ & $27.5 \pm 4.1^{* *}$ & $64 \pm 15$ & 100 \\
\hline Hypoth & 10 & $268 \pm 13$ & $14.4 \pm 1.8^{* *}$ & $25.8 \pm 3.7^{* *}$ & $82 \pm 27$ & 100 \\
\hline
\end{tabular}

a; See Fig. 4.

b : $\mathrm{OCH}=\frac{\text { left ovarian weight }- \text { right ovarian weight }}{\text { right ovarian weight }} \times 100 \%$

c: $\quad$ IS $=\frac{\text { no. of rats without } C L}{\text { no. of treated rats }} \times 100 \%$

d: Mean \pm S.E.

* and **: Values significantly different from those of intact controls at the levels of 1 and $0.1 \%$, respectively (Student's $t$-test). 


\section{Discussion}

A sterility syndrome characterized by acyclicity and anovulation can be induced in adult female rats by electrocauterization of the anterior hypothalamus (D'Angelo and Kravatz, 1960) or by neuronal deafferentation by means of a Halász knife (Halász and Gorski, 1967) separating the same area of the hypothalams from the ventromedial-arcuate (VMH-ARC) region. These findings suggest that neuronal components in the anterior hypothalamus appear to be responsible for the cyclicity in gonadotropin secretion. Accordingly, in female rats rendered acyclic by neonatal treatment with sex steroids, it seems likely that the anterior hypothalamus might be irreversibly altered. Nadler $(1968,1972)$, however, postulated that the primary site affected by neonatal treatment with androgen was the VMH-ARC area but not in the preoptic-anterior hypothalamic region (POAAHA), on the basis of his findings that anovulatory sterility was induced by micropellets containing TP implanted into the VMH-ARC area but not by those placed in the POA-AHA. In contrast, since it was impossible to localize sensitive areas within the hypothalamus by placing TP crystals in different regions for 24-72 hrs, Hayashi and Gorski (1974) concluded that components sensitive to androgen might be scattered rather than confined to a special area in the hypothalamus.

1) The presence of aromatizing enzyme in the hypothalamus which converts androgens to estrogens (Naftolin et al., 1971, 1972; Weisz and Gibbs, 1974), 2) failure of neonatal treatment with non-aromatizable androgen, e.g. $5 \alpha$-dihydrotestosterone, to induce sterility in female rats (McDonald and Doughty, $1972 b, 1974)$ and 3) inhibition of the masculinizing effect of neonatal androgen by simultaneous administration of antiestrogen MER-25 (McDonald and Doughty, 1972a,
1973) lend support to the concept that aromatization of androgens is a prerequisite for inducing sterilization in neonatal female rats. Sutherland and Gorski (1972) reported that infusion of $1 \mu \mathrm{g}$ estradiol benzoate in the hypothalamus of 2-day-old females invariably induced a sterility syndrome associated with polyfollicular anovulatory ovaries, while infusion of 0.1 and $0.01 \mu \mathrm{g}$ of the estrogen resulted in sterility in 2 of 7 and 2 of 6 rats, respectively. The results of the present experiments are consistent with those of Sutherland and Gorski, since implantation of a pair of pellets each containing $2 \mu \mathrm{g} \mathrm{E}_{2}$ into the brain of 5-day-old female rats evoked sterility regardless of loci of pellets, while a pair of pellets containing $0.2 \mu \mathrm{g} \mathrm{E}_{2}$ induced sterility only when placed in the anterior hypothalamus, those located in the medial to posterior hypothalamus being without effect in this respect. If it is true that aromatization of androgens. in the hypothalamus is prerequisite for sterilization it likely takes place in the anterior hypothalamus.

Recently, Döcke and Dörner (1975) obtained anovulatory syndrome by implantation of paraffin micropellets containing $0.5 \%$ estradiol benzoate (EB) into mediobasal hypothalamus. According to them, the EBparaffin micropellets in POA-AHA or VMHARC region effectively induced sterility, while in the present study the paraffin pellets containing $1 \% \quad \mathrm{E}_{2}$ in POA-AHA region induced sterility but those in dorsomedialposterior hypothalamus region did not. It is suggested, therefore, that the sites of action of estrogen in this sterilizing effect are the former two regions but not the latter one. 


\section{Acknowledgements}

The author expresses his thanks to Miss $\mathrm{H}$. Nagashima for her technical assistance throughout the course of the experiments. He is also indebted to Prof. K. Takewaki, Kawasaki Medical College, for his valuable criticism and help in preparing the manuscript. This work was partly supported by Reseach Grant from the Ministry of Health and Welfare of Japan.

\section{References}

Arai, Y. Neuroendocrine Control (edited by K. Yagi and S. Yoshida). Univ. Tokyo Press, Tokyo, p. 27 (1973).

Brown-Grant, K. (1974). J. Endocr. 62, 683.

D'Angelo, S.A. and A.S. Kravatz (1960). Proc. Soc. Exp. Biol. Med. 104, 130.

Döcke, F. and G. Dörner (1975). Endokrinologie 65,375 .

Gorski, R. A. Frontiers in Neuroendocrinology (edited by L. Martini and W.F. Ganong). Oxford Univ. Press, N.Y., p. 237 (1971).
Halász, B. and R.A. Gorski (1967). Endocrinology 80,608 .

Hayashi, S. (1974). Endocrinol. Japon. 21, 453.

Hayashi, S. and R.A. Gorski (1974). Endocrinology 94, 1161.

König, J.F.R. and R.A. Klippel, The Rat Brain. Williams and Wilkins Co., Baltimore (1963).

McDonald, P.G. and C. Doughty (1972a). J. Endocr. $55,455$.

McDonald, P.G. and C. Doughty (1972b). J. Reprod. Fert. 30, 55.

McDonald, P.G. and C. Doughty (1973). Neuroendocrinology 13, 182.

McDonald, P.G. and C. Doughty (1974). J. Endocr. 61, 95.

Nadler, R.D. (1968). J. Comp. Physiol. Psychol. 66, 157.

Nadler, R.D. (1972). Neuroendocrinology 9, 349.

Naftolin, F., Ryan, K.J. and Z. Petro (1971). J. Clin. Endocr. 33, 368.

Naftolin, F., Ryan, K.J. and Z. Petro (1972). Endocrinology 90, 285.

Sutherland, S.D. and R.A. Gorski (1972). Neuroendocrinology 10, 94.

Takewaki, K. (1962). Experientia 18, 1.

Wagner, J.W., Erwin, W and V. Critchlow (1966). Endocrinology 79, 1135.

Weisz, J. and C. Gibbs (1974). Endocrinology 94, 616. 